\title{
UN EJEMPLO ILUSTRATIVO DEL PROCESO DE CAMBIO ENTRE EL VILLANCICO RENACENTISTA Y EL BARROCO
}

\author{
Mariano LAMBEA \\ Departamento de Musicología, CSIC, Barcelona
}

\begin{abstract}
After a brief and general historical comment about different aspects of Baroque mentality, the article intends to illustrate the process of change which takes place, at different levels of appreciation, between Renaissance and Baroque Christmas carols. To do so, both musical versions of the old traditional refrain entitled "No puedo apartarme", coming respectively from an anonymous composer from the Cancionero Musical de Palacio $\left(15^{\text {th }}-16^{\text {th }}\right.$ centuries) and from Juan Vásquez in his Recopilación de Sonetos y Villancicos (1560), are compared. Lastly, these two Renaissance versions are compared to the Baroque carol "Madre, el amor" (early $17^{\text {th }}$ century) by Joan Pau Pujol, whose refrain, more modern and learned, offers a similar literary theme, yet its music is more evolved and elaborate.
\end{abstract}

\section{Resumen}

Tras un breve comentario histórico de carácter general sobre diversos aspectos de la mentalidad barroca, el artículo intenta ilustrar el proceso de cambio que se da, a diversos niveles de apreciación, entre el villancico renacentista y el barroco. Para ello se procede a confrontar las dos versiones musicadas del antiguo estribillo de carácter tradicional titulado «No puedo apartarme», procedentes, respectivamente, de un compositor anónimo en el Cancionero Musical de Palacio (siglos XV-XVI) y de Juan Vásquez en su Recopilación de Sonetos y Villancicos (1560). Por último se comparan estas versiones renacentistas con el villancico barroco «Madre, el amor» (principios del siglo XVII) de Joan Pau Pujol, cuyo estribillo, más moderno y de creación culta, ofrece una temática literaria parecida pero, musicalmente, es más evolucionado y elaborado.

Son varios, y trascendentales, los hechos históricos, sociales y culturales acaecidos en el cruce de los siglos XVI y XVII, que hacen de España un país en el que las cosas suceden de una manera extrema y radical. En el ámbito político y económico, la monarquía de los Austrias va a asistir impotente a la progresiva corrupción de sus instituciones y al deterioro del imperio heredado a lo largo del siglo XVI. En el plano religioso y espiritual, España era una de las naciones que se había opuesto con más virulencia a la reforma luterana, y con su actitud contrarreformista había hecho posible que se mantuvieran vigentes - en las estructuras del poder y en la mentalidad de las gentes - las tesis expuestas en el Concilio de Trento (1545-1563). Pero, paradójicamente, en ese ambiente en el que los poderes político y religioso se mostraban más intransigentes y se preocupaban casi exclusivamente del aparato exterior y la imposición dogmática, va a sur- 
gir un movimiento literario y artístico de gran esplendor, que la historiografía posterior no dudará en calificar de «Siglo de Oro» ${ }^{1}$.

En esta época dorada que tratamos, la sensibilidad y la mentalidad renacentista están sufriendo un proceso de cambio, y, a medida que sus rasgos de equilibrio y de belleza estática se van transformando, las nuevas modas imponen paulatinamente un gusto más teatralizado y gestual en las artes, en las letras y en las normas sociales de comportamiento. La hiperbolización de las formas clásicas dará paso a una transformación dinámica del modelo renacentista que irá encontrando su propio camino en la creciente expresividad de la experimentación manierista, antesala del espíritu barroco. Es verdad que la transición será lenta al principio, pero cada vez más perceptible conforme vaya avanzando el siglo XVII, ya que los cambios evolutivos en la historia del arte obedecen, por lo general, a procesos de maduración cuyos condicionantes no son siempre fáciles de precisar, pues se deben a motivaciones de diversa índole. Sin embargo, se dan ocasiones clarísimas de cambios bruscos en la trayectoria de los estilos artísticos que rompen abruptamente con el pasado.

Todos sabemos que el arte barroco es un arte integrador y espectacular, que fue potenciado y promovido por el poder político y religioso para legitimar y dar credibilidad a sus propias ideas y propósitos. Cabe matizar, sin embargo, que no faltaron artistas que mantuvieron una postura crítica contra los sistemas imperantes, o, al menos, en sus obras y posturas se desmarcaron de las directrices ideológicos impuestas. Pero, para nuestra intención es interesante observar ahora, cómo el poeta y el músico ya no se contentan con recrear y comentar el villancico del período renacentista dentro de unos límites equilibrados, sino que lo van a recargar cada vez más; y esto por influencia del ambiente político y religioso que les exigirá una mayor ostentación, un mayor compromiso con su cometido social y una decidida intención propagandística.

Antes de proseguir, permítaseme una pequeña digresión sobre el villancico renacentista: a pesar de que la historia general del villancico literariomusical ${ }^{2}$ está aún por escribir y seguramente lo estará por mucho tiempo, pues tendría que ser una obra inmensa, fruto de la dedicación de un grupo de investigadores - filólogos y musicólogos - que trabajaran en equipo, y también porque faltan aún muchísimos de ellos por transcribir y publicar, y hasta por catalogar, a pesar de todo esto, digo, el proceso diacrónico de su evolución puede seguirse paso a paso, a la luz de los que se han publicado y estudiado hasta el momento. Y es entonces cuando se puede hablar de un villancico profano o civil y de un villancico sacro o religioso, de un villancico amoroso y de

1. Cfr. con Nicolás Marín López: Estudios literarios sobre el Siglo de Oro, (2a edición, aumentada, al cuidado de Agustín de la Granja), Granada, Universidad de Granada, 1994, interesa la "Meditación del Siglo de Oro", pp. 11-29.

2. La imprescindible monografía de Antonio SÁNCHEZ RomERALO: El villancico. (Estudios sobre la lírica popular en los siglos XV y XVI), (Biblioteca Románica Hispánica, II. Estudios y ensayos, 131), Madrid, Editorial Gredos, 1969, se refiere al estilo, evolución y aspectos literarios del género, pero no trata de la música. Sobre el itinerario del villancico literariomusical, vid., entre otros, el trabajo clásico de José SuBIRÁ: "El villancico literario-musical. Bosquejo histórico", Publicaciones de "Revista de Literatura", Tomo XXII, Julio-Diciembre de 1962, pp. 5-27; y el excelente "Calendario del villancico" de Carlos Villanueva: Los villancicos gallegos, La Coruña, Fundación Pedro Barrié de la Maza, 1994, pp. 33-72. 
uno cortesano, de un villancico a dos voces y de otro a dos coros, de un villancico renacentista y de uno barroco, o mejor aún — siguiendo nuevas metodologías para el estudio de las ciencias históricas que no gustan de acotar la historiografía en términos convencionales de filiación estética, sino que prefieren hacerlo en términos meramente cronológicos-: de un villancico del siglo XVI, de uno del XVII, etc., o por mitades y tercios de centuria, si conviene. Cuando se dan todas estas circunstancias que acabo de enumerar, es cuando el villancico ha perdido ya su rusticidad y su perfume popular de origen. Ahora no se transmite oralmente sino por escrito; ha salido del campo y ha recalado en la ciudad, en la corte, en la iglesia; en definitiva, se ha intelectualizado y racionalizado, y en muchas ocasiones tiene ya un creador con nombre y apellidos (al menos en la música; en el texto poético es más difícil averiguar el nombre del autor, aunque, evidentemente, lo tendría en el momento en que se creó, y no como el villancico popular que es creado y recreado por la voz anónima y tradicional del pueblo en un lapso cronológico imposible de determinar).

Por otra parte, es muy sugestiva la idea —apuntada por historiadores, filólogos e investigadores $^{3}$, y retomada de continuo- que estudia, analiza o justifica el reciclaje estilístico del villancico popular antiguo en época renacentista, en unos términos que a mí me gustaría sintetizar de la siguiente manera: una de las características generales de ese complejo movimiento cultural, ideológico y artístico que conocemos con el nombre de Renacimiento - y de su expresión más fructífera y atrayente como fue el Humanismo - es su idealización de la naturaleza y su inclinación por los valores populares, al menos desde la perspectiva de la ficción literaria. El anhelo espiritual de la época en volver a la idílica «auræ ætas» en la que el hombre había sido feliz con sólo rememorar su procedencia y semejanza divinas, hizo posible que surgiera un decidido intento de actualizar la placidez de aquel tiempo pasado. El hombre renacentista dirigió, pues, una mirada hacia la Antigüedad para afrontar las dudas de su presente, para reconstruir aquella Arcadia que ahora, súbitamente, había aparecido rota entre sus manos por la guerra, la ambición, los errores humanos...

Se creyó ver en la figura del hombre llano, simple e incontaminado por la civilización, una especie de encarnación neoplatónica de la bondad natural. De ahí a sublimar la canción popular que plasmaba los encantos de la vida rústica y aldeana mediaba sólo un paso; y el paso fue dado, en el ámbito de la literatura, a través de una moda que desembocó en el gusto por la poesía lírica de tipo tradicional, por aquellas «cancioncillas», al decir de los filólogos, que cantaban los villanos. La Edad Media había legado al Renacimiento todo este caudal lírico de villancicos en estado rústico. Pero el poeta renacentista, hombre culto, humanista, conocedor de la preceptiva y de la métrica, ahora instalado en la corte e inmerso en la vida urbana, no vino a conformarse con recibir el tesoro medieval de aquella lírica en estado «hipotéticamente» puro y

3. Vid., entre otros, Américo CASTRO: El pensamiento de Cervantes, (Nueva edición ampliada y con notas del autor y de Julio Rodríguez-Puértolas), Barcelona-Madrid, Ed. Noguer, 1972, pp. 175-176 (1ª ed. 1925); Dámaso Alonso y José M. Blecua: Antología de la poesía española. Poesía de tipo tradicional, (Biblioteca Románica Hispánica, VI. Antología Hispánica), Madrid, Editorial Gredos, 1956, pp. LI-LII de la "Introducción por José Manuel Blecua"; y Margit FrENK AlATORRE: Estudios sobre lírica antigua, Madrid, Editorial Castalia, 1978, pp. 47-51 sobre la "Dignificación de la lírica popular en el Siglo de Oro". 
a manejarlo sin añadir nada personal, sino que, con mano culta, lo modificó a través de una amplificación que contemplaba diversas facetas, entre las que destacan la elaboración de la glosa correspondiente, la imitación temática, el contrafactum a lo divino, la intercalación recurrente, la inclusión en tratados eruditos, la incorporación al acervo cultural; así pues, el poeta cortesano «comentó» ese minúsculo estribillo o cancioncilla tradicional mediante el concurso de la razón y de la aplicación de las reglas de la preceptiva literaria, y, naturalmente, desde su propia inspiración poética y aliento creador, y recreador. Por decirlo en una palabra: consideró que era necesario revestir el villancico aldeano con un ropaje artístico y acicalarlo para presentarlo en sociedad $^{4}$.

Volvamos ahora al villancico barroco y, por extensión, al espíritu barroco ${ }^{5}$, en el que el gran escaparate y la lujosa fiesta que lo acompaña y lo ensalza hasta la extenuación no son más que el envoltorio multicolor que oculta la verdadera amargura y la profunda melancolía que se adivinan tras ellos. Por eso el hombre barroco español - y me refiero a toda la sociedad sin distinción de clases ni de privilegios-, consciente de la desmembración del imperio, de las crisis económicas, de las continuas guerras, de las epidemias y del hambre, y, sobre todo, de su fracaso social y existencial, se volcará hacia una honda espiritualidad, hacia una búsqueda desmedida de la fe en la vida futura, que le reconforte de la desesperación de la vida presente.

Ante esta nueva situación que he descrito genéricamente - porque ya ha sido estudiada a fondo por historiadores e hispanistas de prestigio y no es cuestión de ir repitiendo aquí lo que ya se ha dicho en diferentes lugares y de mil maneras distintas-, el villancico renacentista - me refiero al que recogía la cancioncilla tradicional y cantaba las excelencias de la vida pastoril, los gozos del amor o los sinsabores del desamor- experimentará de lleno estos síntomas de cambio, y poco a poco irá perdiendo su perfume popular tan característico, hasta convertirse en un villancico más artificioso, más rebuscado y complicado, con mayor poder alegórico y con mayor carga simbólica; en definitiva, se "amanerará" y se "barroquizará", desbordando el molde renacentista en el que se había desarrollado hasta ahora. Intentaré ilustrar este proceso de cambio de la siguiente manera:

En el Renacimiento, un compositor anónimo del Cancionero Musical de Palacio ${ }^{6}$ (siglos XV-XVI) (Ejemplo musical n ${ }^{\circ}$ ) pondrá música a este "cantar viejo":

4. Para las sucesivas etapas de la dignificación de la lírica popular, ibídem, pp. 51-80.

5. Vid. el excelente libro de F. R. DE LA FLOR: La península metafísica. Arte, literatura y pensamiento en la España de la Contrarreforma, Madrid, Biblioteca nueva, 1999.

6. La Música en la Corte de los Reyes Católicos. Cancionero Musical de Palacio (Siglos XV-XVI), Vol. 2 (III, Polifonía profana), edición de Higinio ANGLÉS (Monumentos de la Música Española, X), Barcelona, Consejo Superior de Investigaciones Científicas, 1951, p. 122 de la parte musical. El Cancionero Musical de Palacio había sido editado anteriormente por Francisco AsENJo BARBIERI con el título Cancionero musical de los siglos XV y XVI, Madrid, Tipografía de los Huérfanos, 1890; la pieza que nos ocupa se halla entre las pp. 427-428; y, asimismo, en la edición de Buenos Aires, Editorial Schapire, 1945, pp. 433-434, con el mismo título. 
No puedo apartarme

de los amores, madre,

¡no puedo apartarme! ${ }^{7}$

"Bello estribillo arcaico, con la confesión de la niña a la madre" comenta José Romeu ${ }^{8}$. En efecto, es candoroso, espontáneo, directo, pero, sobre todo, parece que esté muy acorde con las necesidades naturales y vitales de una muchacha, que se limita a resignarse al no poder desvincularse del amor terrenal; al menos así lo reafirma en la siguiente glosa, la cual, según Romeu, es de creación "más reciente":

Amor tiene aquesto

con su lindo gesto,

que prende muy presto

y suelta muy tarde 9 .

Rebasada la segunda mitad del siglo XVI, el músico Juan Vásquez (ca. 1500-ca. 1571), en su Recopilación ${ }^{10}$, retomará el estribillo para ponerle otra música diferente; pero relativamente diferente (Ejemplo musical $n^{\circ} 2$ ). En efecto, obsérvese que la música de la voz superior en los dos primeros versos es igual en ambas versiones, variando, únicamente, los valores de las notas y las acentuaciones al tratarse de un compás ternario y otro binario ${ }^{11}$. La composición de Vásquez es más extensa y elaborada, con detalles de contrapunto imitativo que contrastan con la escritura vertical, la homofonía y la sencillez estructural de la versión anónima. De la misma manera que el estribillo literario pertenece, sin duda, al tesoro de la lírica popular, puede pensarse también que parte de la música pudiera pertenecer, asimismo, al acervo tradicional, siendo utilizada por diferentes compositores con compás, estilo de escritura, modalidad y acompañamiento de consonancias $^{12}$ distintos.

La glosa de la pieza de Vásquez es más breve:

7. Vid. Margit Frenk: Corpus de la antigua lírica popular hispánica (siglos XV a XVII), Madrid, Editorial Castalia, 1987, (2 ed.), p. $115, \mathrm{n}^{\circ} 247$ A y $247 \mathrm{~B}$, donde constan todas las fuentes literarias y musicales.

8. La Música en la Corte de los Reyes Católicos, IV-2 Cancionero Musical de Palacio, (Siglos XV-XVI), Vol. 3-B, edición de José Romeu Figueras (Monumentos de la Música Española, XIV-2), Barcelona, Consejo Superior de Investigaciones Científicas, 1965, pp. 442b-443a.

9. Ibídem, p. $442 \mathrm{~b}$.

10. Juan VÁsQueZ: Recopilación de Sonetos y Villancicos a quatro y a cinco, (Sevilla, 1560), edición de Higinio ANGLÉs (Monumentos de la Música Española, IV), Barcelona, Consejo Superior de Investigaciones Científicas, 1946, p. 47 de la parte de los textos y pp. 226-227 de la parte musical.

11. Sería interesante estudiar detenidamente los aspectos formales de la relación música/texto con el fin de observar el funcionamiento del ritmo poético y el musical, especialmente cuando un mismo texto es puesto en música con compases diferentes. En este sentido, sucede lo mismo con el romance anónimo «Entre cercos de carmín» y su estribillo «¡Ay, claras aguas, / cómo viendo las vuestras / temo mudanzas», copiados ambos en dos versiones completamente diferentes, en compasillo y en compás de proporción menor, en el Cancionero poético-musical hispánico de Lisboa (primeras décadas del siglo XVII) (edición de Mariano LAmBEa y Lola Josa, en preparación).

12. Para la expresión "acompañamiento de consonancias" vid. Pedro Cerone: El melopeo y maestro. Tractado de musica theorica y pratica (ed. facsímil de la de Nápoles: Iuan Bautista Gargano y Lucrecio Nucci, 1613), Bologna, Forni editore, 1969, vol. II, pp. 829-832. 
María y Rodrigo

Arman un castillo ${ }^{13}$.

El poeta toledano Sebastián de Horozco (ca. 1510-1580) remedó el estribillo tradicional a lo divino en su Cancionero:

No puedo apartarme

de vos, Virgen y madre;

no puedo apartarme ${ }^{14}$

Entrado el siglo XVII, el compositor y maestro de capilla mataronés Joan Pau Pujol (1570-1626) ${ }^{15}$ musicará este otro estribillo, más complejo; podría decirse que menos espontáneo y más dogmático, y, por supuesto, sin raigambre popular. Se trata de su villancico «Madre, el amor» ${ }^{16}$ (Ejemplo musical $\left.n^{\circ} 3\right)$ :

- Madre, el amor me desvela por comer el Pan de amor.

-Guárdate de su rigor y anda siempre con cautela.- ${ }^{17}$

El contexto ha cambiado: aunque la niña, aquí, también confiesa - en este caso, su desvelo, y explica la causa del mismo, que no es otra que haber conocido el amor al recibir a Jesús sacramentado-, sin embargo, la intervención de la madre impide que su confesión alcance esa inflexión lírica, candorosa que tenía el estribillo tradicional, en el cual la confidencia de madre a hija se daba, en realidad, de mujer a mujer. Es verdad que en este estribillo culto, y popularizante a la vez, se mantienen las protagonistas y el tema de la confesión de amor, pero la madre y la hija ya no son dos mujeres de carne y hueso; ahora son dos conceptos, dos abstracciones en manos del poeta: la voz del alma enamorada, temerosa en su osadía de amar a Dios, y la voz del dogma, de la contrarreforma que avisa y aconseja, y ordena, si es preciso (obsérvese el "rigor" del tercer verso que hace referencia, creo, al estado de gracia indispensable para tomar la comunión).

Así, pues, podemos constatar cómo el poeta culto - no sólo en el caso concreto que nos ocupa, sino en otros muchos también - trastoca los términos, bebe de la fuente tradicional, se

13. Juan VÁsquez: Op. cit., p. 47 de la parte del texto.

14. La Música en la Corte de los Reyes Católicos..., edición de José Romeu Figueras, p. 443a, donde se hace referencia también a la "glosa con cuatro coplas propias «para la noche de Navidad»" que escribió Horozco. Para las obras del poeta vid. José Simón Díaz: Bibliografía de la Literatura Hispánica, Madrid, Consejo Superior de Investigaciones Científicas, 1976, vol. XI, pp. 621-624.

15. Vid. Mariano Lambea Castro: Los villancicos de Joan Pau Pujol (*1570 - †1626). Contribución al estudio del villancico en Cataluña, en el primer tercio del siglo XVII, Bellaterra, Publicacions de la Universitat Autònoma de Barcelona, 1998 (tesis doctoral publicada en microficha). Pau Pujol.

16. Biblioteca de Catalunya, Sign.: M. 769/6. Se trata de un villancico a solo y a 6 vv. Autor de la música: Joan

17. La puntuación de los villancicos de Pujol que he trabajado ha corrido a cargo del Dr. Josep Romeu Figueras, a quien agradezco sinceramente su amabilidad y disposición. 
apropia de lo que le interesa, que es, sobre todo, la figura de la madre, porque sabe que es muy sugestiva, popular y recurrente, que siempre ha sido una interlocutora tradicional y que el pueblo la reconoce enseguida ${ }^{18}$, pero, en el fondo, racionaliza, remedando a lo divino, el tópico de la confidencia de amor entre madre e hija, puesto que aquella cancioncilla tradicional, parca en palabras, en la que todo era puro sentimiento lírico que impactaba y seducía, es ahora una estrofa culta, llena de conceptos, de sutilezas que hay que adivinar, de razones y justificaciones que se dirigen al intelecto más que al sentimiento. Leamos, además, las coplas que acompañan a ese estribillo:

\section{Copla $1^{\text {a }}$}

— ¿Por qué me puede dañar el Pan sabroso y divino?

-Porque Dios, que en pan vino, puede dar vida y matar.

- ¿Y si me promete dar gusto, contento y regalo? $-\mathrm{El}^{19}$ justo, y castiga al malo y al bueno sabe premiar. -Pues, ¿qué haré si me desvela por mil caminos, amor?

-Guárdate de su rigor y anda siempre con cautela.-

\section{Copla $2^{\mathrm{a}}$}

- Sin que comido se acabe, ¿cómo este Pan tanto dura?

-Tiene de pan la figura y que es Dios por fe se sabe. - ¿Cómo en chico lugar cabe, siendo Dios tan sin medida? —En la fe queda escondida de este secreto la llave.

-Pues, ¿qué haré si me desvela con mil deseos, amor?

- Guárdate de su rigor y anda siempre con cautela.-

En cuanto a la música del villancico de Pujol, comparada con la del anónimo del Cancionero Musical de Palacio y la de Juan Vásquez, se ha de comentar que es sensiblemente dife-

18. La presencia de la madre como interlocutora o confidente consta en muchos estribillos tradicionales; como aquellos famosísimos que comienzan: "Tres ánades, madre" y "De los álamos vengo, madre"; cfr. Margit FrENK: Corpus..., pp. 86-87, $\mathrm{n}^{\circ} 182$ A (vid. también el 182 B) y pp. 145-146, nº 309 A y 309 B, respectivamente. También pueden rastrearse los poemas que empiezan por la palabra "madre" en el "Índice de primeros versos" (p. 1219).

19. ¿Estará por "Es"? 
rente a ellas en varios aspectos. Resaltaré sólo algunos de ellos, los más destacados en aras de la brevedad:

En el número de voces: seis en el de Pujol por cuatro en los otros.

En el número de secciones: tres en el de Pujol, que son las siguientes: a) una pequeña introducción en diálogo, con preguntas y respuestas a solo; b) una responsión que actúa a guisa de estribillo de considerable extensión y que viene a suponer una reelaboración temática de la introducción; y c) dos coplas en diálogo a dos voces por dos en los otros, los cuales constan de: a) el estribillo; y b) una pequeña glosa que, a efectos formales, puede equipararse a la copla.

En la extensión de la obra: 224 compases para la de Pujol; 12 para la del anónimo del Cancionero Musical de Palacio y 48 para la de Juan Vásquez.

En la textura contrapuntística: ausencia de contrapunto imitativo en el anónimo del Cancionero Musical de Palacio, ligera presencia en el de Vásquez, y elaboración sistemática de esta técnica en el de Pujol (Ejemplo musical $\left.n^{\circ} 4\right)^{20}$.

En la melodía: simplemente destacar en este aspecto la exposición melódica en el villancico de Pujol, en el que destacan su bondad, flexibilidad y equilibrio (Ejemplo musical $n^{\circ} 5$ ); los otros dos villancicos apenas tienen desarrollo melódico.

Como colofón a este breve trabajo incluiré el siguiente texto de Margit Frenk que bien puede sintetizar el proceso de cambio al que he hecho referencia; proceso que concierne, a partes iguales, a la poesía y a la música:

"Para complacer y atraer al hombre de la calle, se tocan las cuerdas que más le suenan; no es que se le devuelva intacta su propia literatura: se le ofrece algo parecido, pero infinitamente renovado, remozado, capaz de deslumbrarlo y conquistarlo.

»[...] los poetas cultos de fines del siglo XVI crean para el pueblo español una nueva poesía popular, tan vieja y a la vez tan atractivamente distinta, que no puede sino invadir el gusto de la gente, haciendo caer en el olvido los cantares antiguos"21.

\section{Bibliografía}

Alonso, Dámaso y Blecua, José M.: Antología de la poesía española. Poesía de tipo tradicional, (Biblioteca Románica Hispánica, VI. Antología Hispánica), Madrid, Editorial Gredos, 1956.

Cancionero musical de los siglos XV y XVI, edición de Francisco AsENJo BARBIERI, Madrid, Tipografía de los Huérfanos, 1890.

20. Agradezco a Raül Benavides su amable disposición y competencia en la realización informática de los ejemplos musicales $n^{\circ} 4$ y 5 del presente trabajo.

21. Margit Frenk Alatorre: Estudios..., p. 66 ("Dignificación de la lírica popular en el Siglo de Oro"). 
Cancionero musical de los siglos XV y XVI, edición de Francisco AsEnjo BARBIERI, Buenos Aires, Editorial Schapire, 1945.

Cancionero poético-musical hispánico de Lisboa (edición de Mariano LAMBEA y Lola JosA, en preparación).

CAStro, Américo: El pensamiento de Cervantes, (Nueva edición ampliada y con notas del autor y de Julio Rodríguez-PuÉrtolas), Barcelona-Madrid, Ed. Noguer, 1972.

CERone, Pedro: El melopeo y maestro. Tractado de musica theorica y pratica (ed. facsímil de la de Nápoles: Iuan Bautista Gargano y Lucrecio Nucci, 1613), Bologna, Forni editore, 1969, 2 vols.

Frenk Alatorre, Margit: Estudios sobre lírica antigua, Madrid, Editorial Castalia, 1978.

Frenk, Margit: Corpus de la antigua lírica popular hispánica (siglos XV a XVII), Madrid, Editorial Castalia, 1987.

La Música en la Corte de los Reyes Católicos, IV-2 Cancionero Musical de Palacio, (Siglos XV$X V I$ ), Vol. 3-B, edición de José Romeu Figueras (Monumentos de la Música Española, XIV-2), Barcelona, Consejo Superior de Investigaciones Científicas, 1965.

La Música en la Corte de los Reyes Católicos. Cancionero Musical de Palacio (Siglos XV-XVI), Vol. 2 (III, Polifonía profana), edición de Higinio ANGLÉs (Monumentos de la Música Española, X), Barcelona, Consejo Superior de Investigaciones Científicas, 1951.

Lambea Castro, Mariano: Los villancicos de Joan Pau Pujol (*1570-†1626). Contribución al estudio del villancico en Cataluña, en el primer tercio del siglo XVII, Bellaterra, Publicacions de la Universitat Autònoma de Barcelona, 1998 (tesis doctoral publicada en microficha).

MARÍn LóPez, Nicolás: Estudios literarios sobre el Siglo de Oro, (2 ${ }^{a}$ edición, aumentada, al cuidado de Agustín DE LA Granja), Granada, Universidad de Granada, 1994.

Pujol, Joan Pau: «Madre, el amor», villancico a solo y a seis voces. Biblioteca de Catalunya, signatura M. 769/6.

R. DE LA FLOR: La península metafísica. Arte, literatura y pensamiento en la España de la Contrarreforma, Madrid, Biblioteca nueva, 1999.

SÁnCHEZ Romeralo, Antonio: El villancico. (Estudios sobre la lírica popular en los siglos XV y XVI), (Biblioteca Románica Hispánica, II. Estudios y ensayos, 131), Madrid, Editorial Gredos, 1969.

Simón DíAZ, José: Bibliografía de la Literatura Hispánica, vol. XI, Madrid, Consejo Superior de Investigaciones Científicas, 1976.

SubIRÁ, José: "El villancico literario-musical. Bosquejo histórico", Publicaciones de "Revista de Literatura", Tomo XXII, Julio-Diciembre de 1962.

VÁSQueZ, Juan: Recopilación de Sonetos y Villancicos a quatro y a cinco, (Sevilla, 1560), edición de Higinio ANGLÉs (Monumentos de la Música Española, IV), Barcelona, Consejo Superior de Investigaciones Científicas, 1946.

Villanueva, Carlos: Los villancicos gallegos, La Coruña, Fundación Pedro Barrié de la Maza, 1994. 


\section{Ejemplos musicales}

Ejemplo musical $n^{\circ} 1$ :

\section{No puedo apartarme}
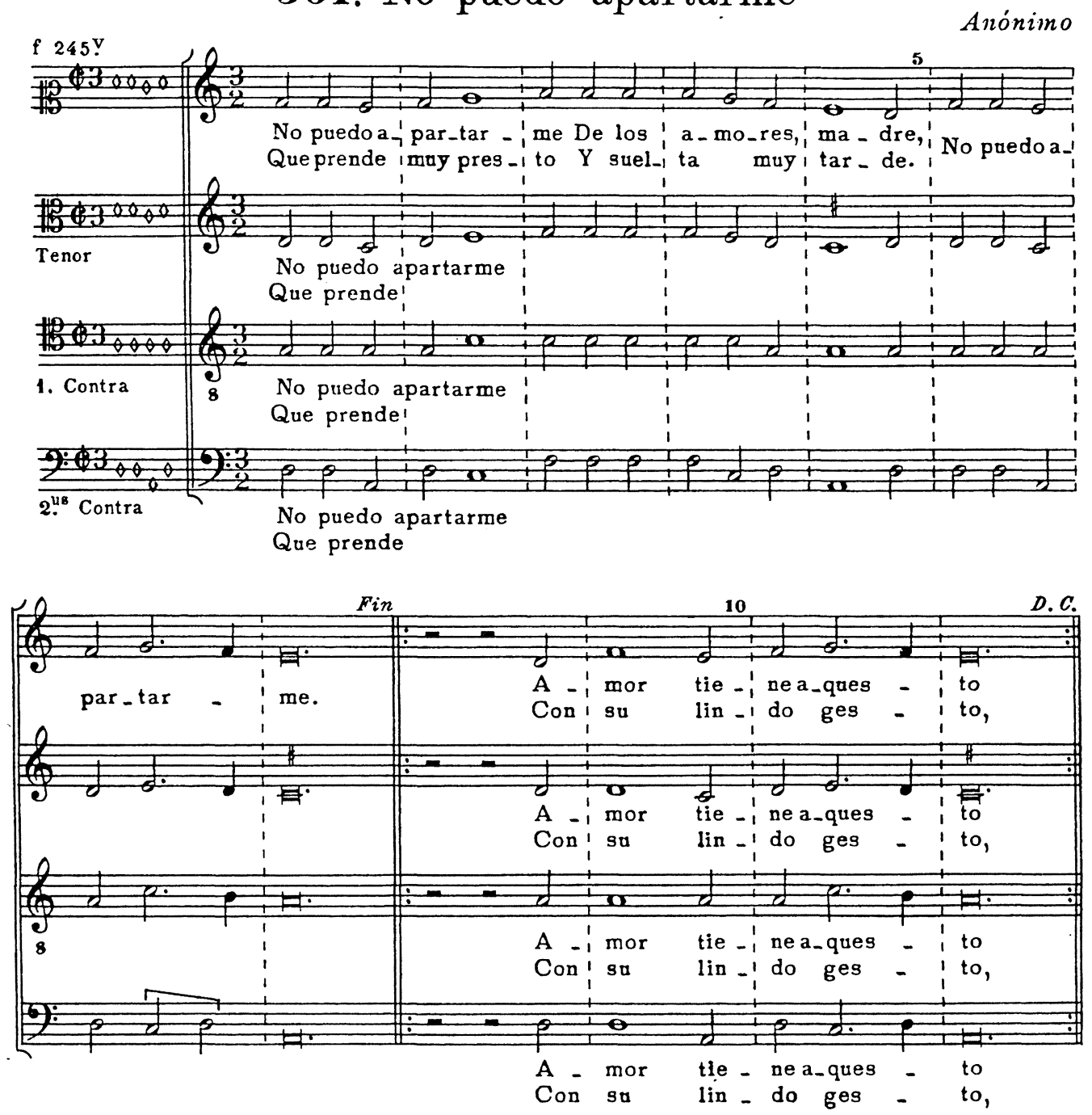

La Música en la Corte de los Reyes Católicos.

Cancionero Musical de Palacio (Siglos XV-XVI)..., p. 122. 
Ejemplo musical $n^{o} 2$

\section{No puedo apartarme}
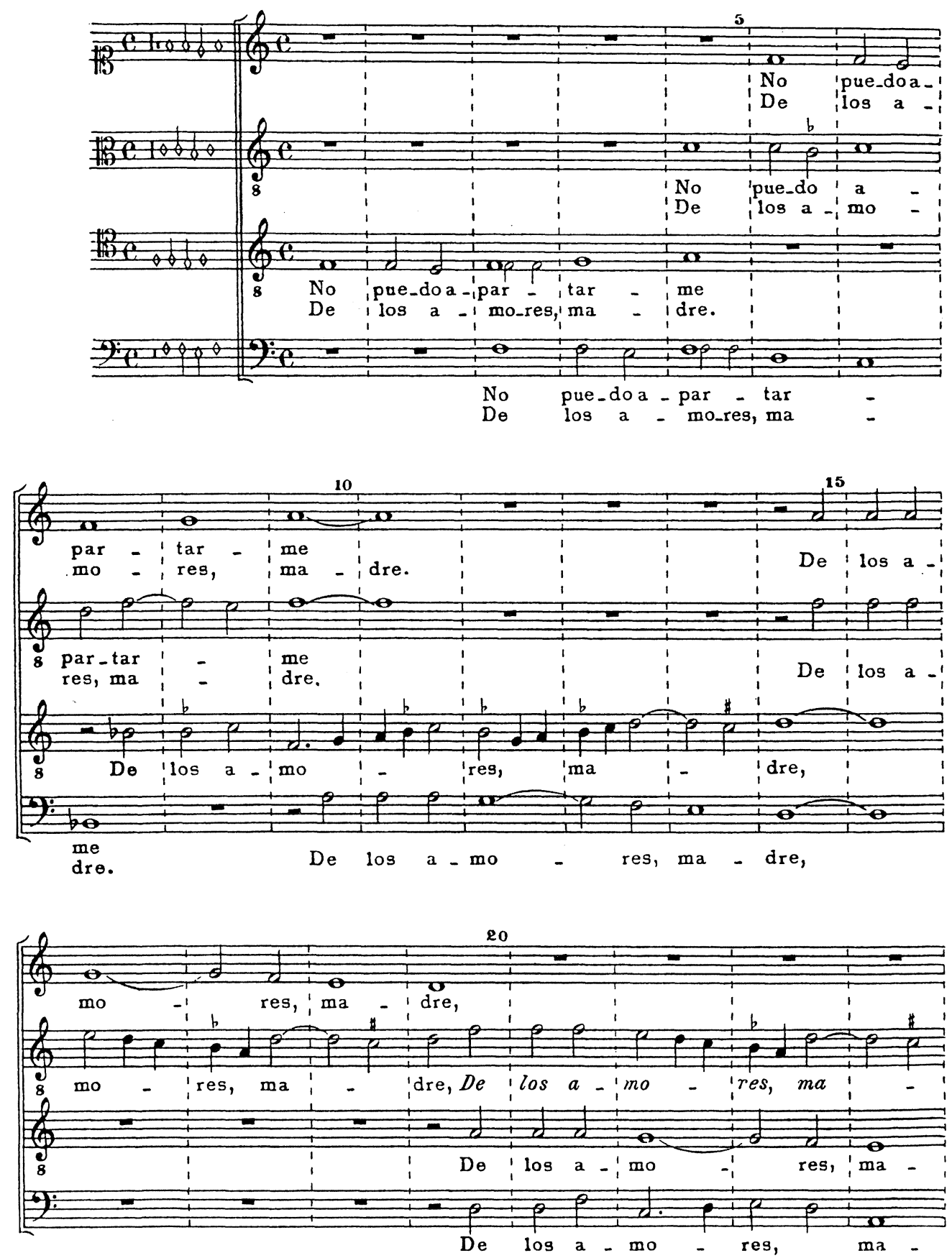

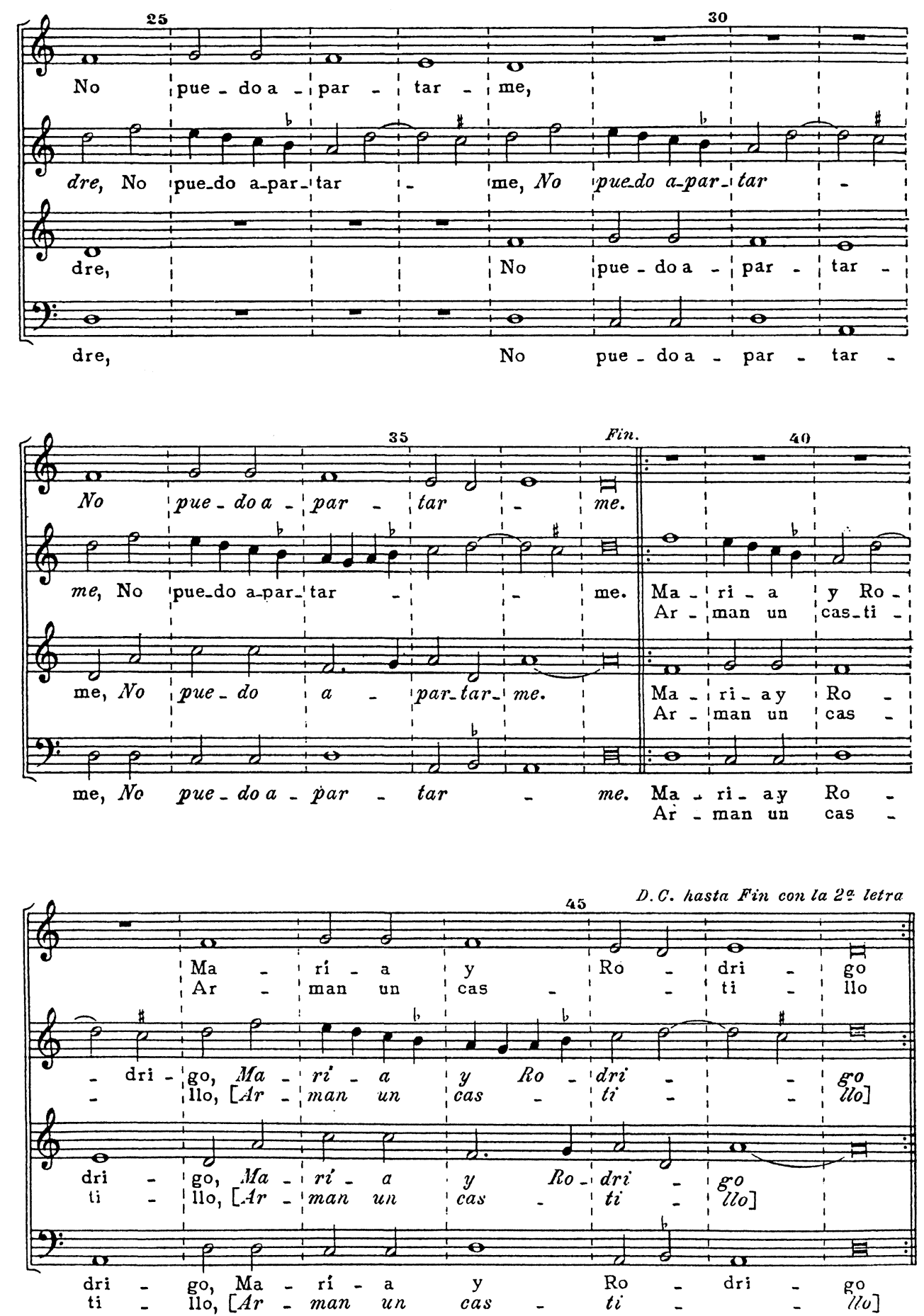

Juan Vásquez: Recopilación de Sonetos y Villancicos a quatro y a cinco..., pp. 226-227.

70

(c) Consejo Superior de Investigaciones Científicas Licencia Creative Commons 3.0 España (by-nc)
Anuario Musical, 56 (2001)

http://anuariomusical.revistas.csic.es 
Ejemplo musical $n^{o} 3$

Cantus $P \rho, 6$,

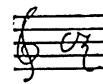

Cantus 2?A, 6,

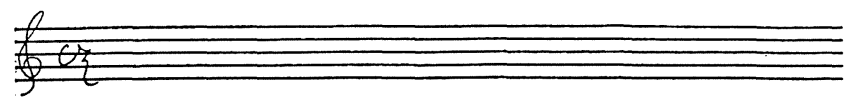

Altus Pregunta solo

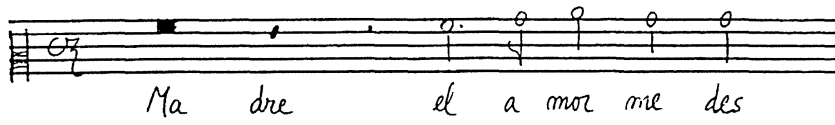

Terror sole Respuesta

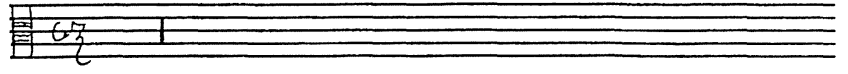

Tent 29 A, 6

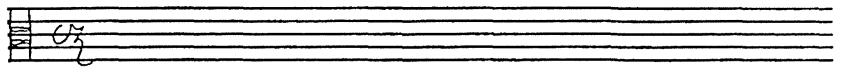

Bavike H, 6 ,
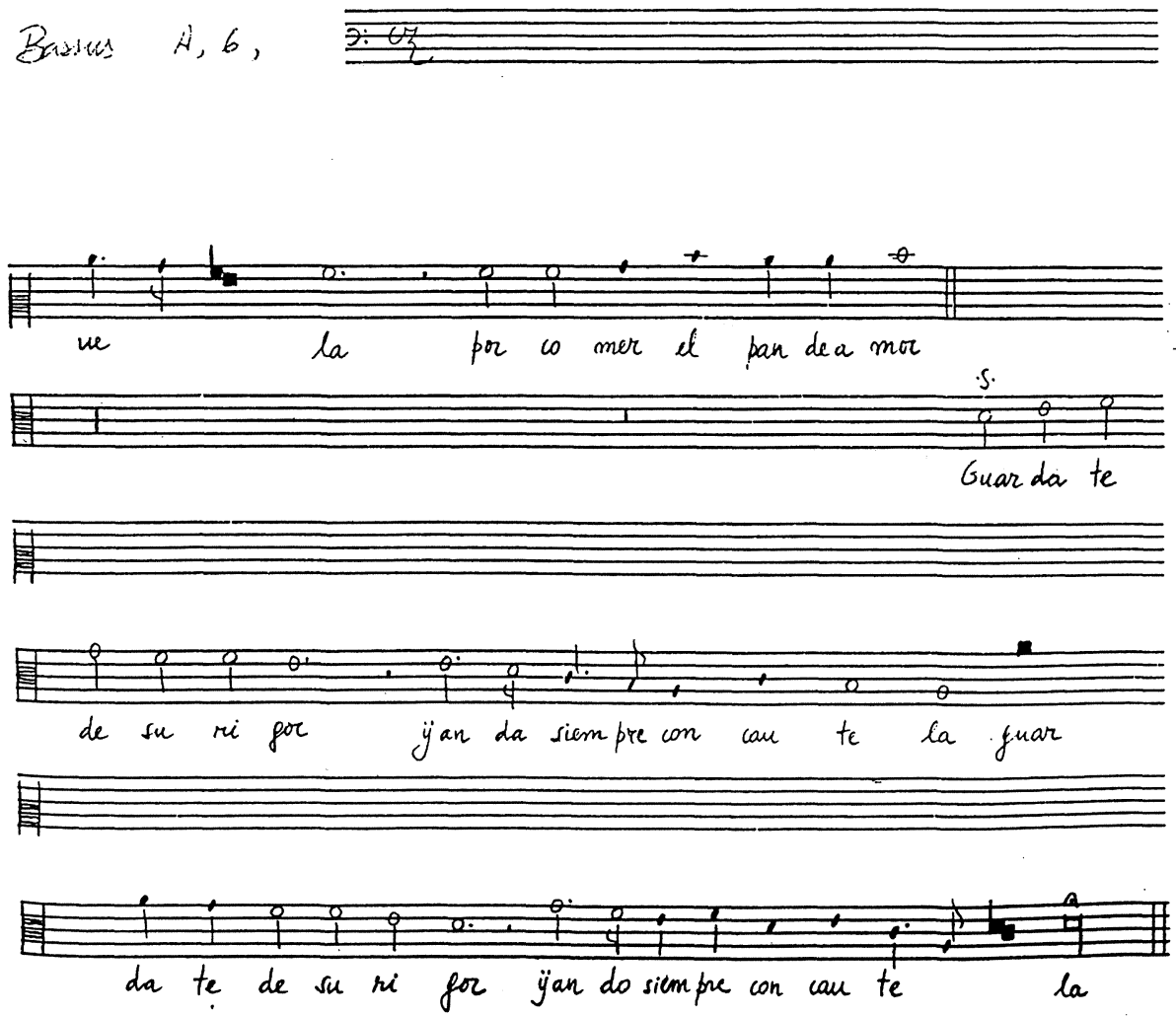

Joan Pau Pujol: Villancico «Madre, el amor».

Mariano Lambea Castro: Los villancicos de Joan Pau Pujol $(* 1570-\uparrow 1626) \ldots$, vol. III, p. 194

(transcripción paleográfica). 
Ejemplo musical $n^{\circ} 4$
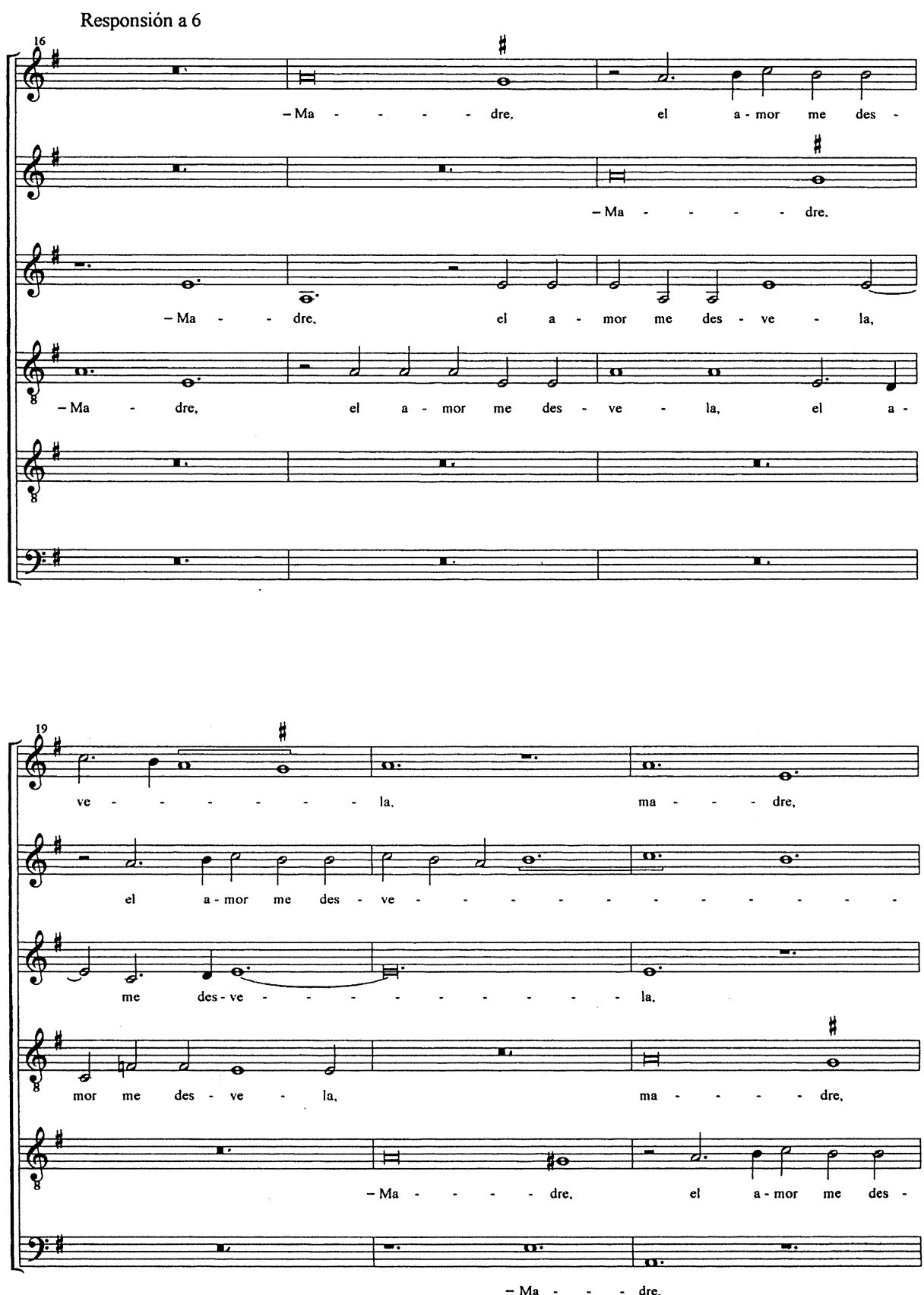

Joan Pau Pujol: Villancico «Madre, el amor».

Mariano Lambea Castro: Los villancicos de Joan Pau Pujol (*1570-†1626)..., vol. IV, p. 195 (edición diplomático-interpretativa en notación moderna). 
Ejemplo musical $n^{\circ} 5$

Tiple I

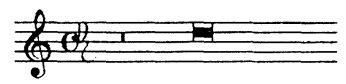

Tiple II

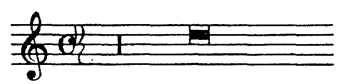

Alto

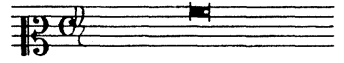

Tenor I

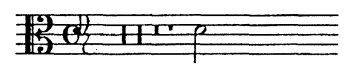

Tenor II

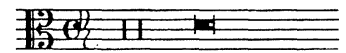

Bajo

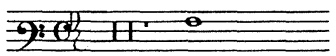

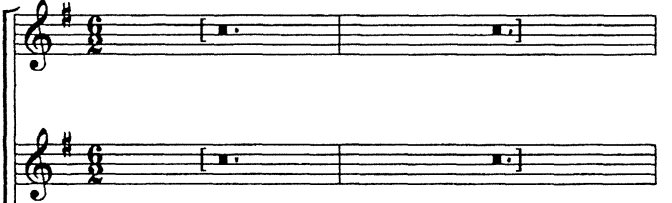

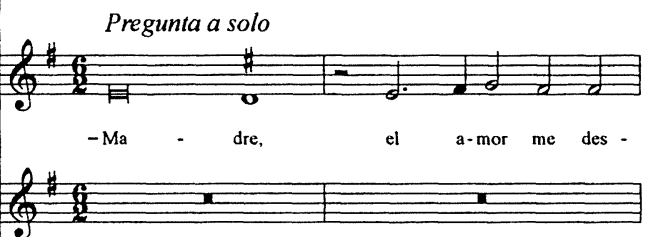

8
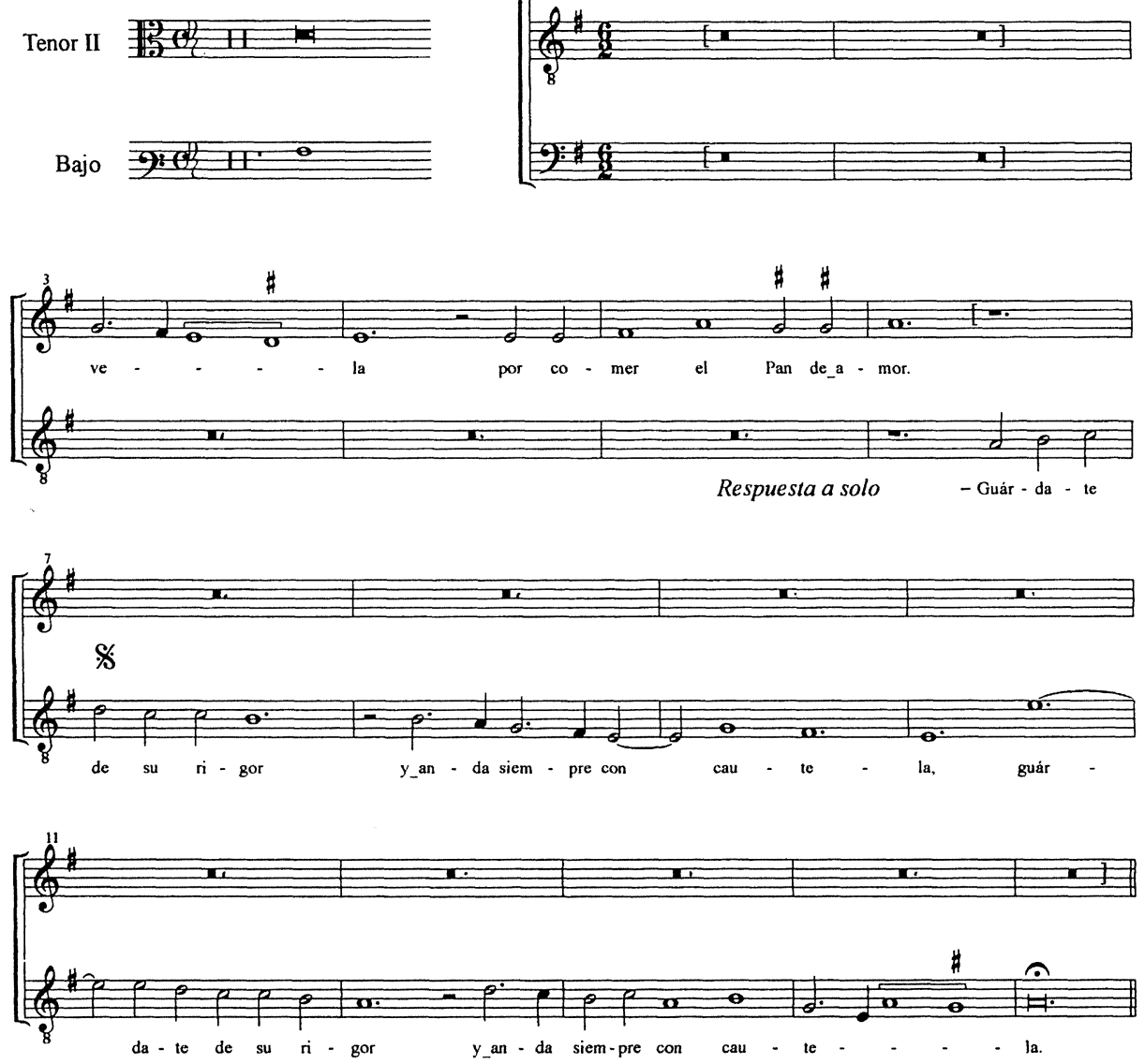

Joan Pau Pujol: Villancico «Madre, el amor».

Mariano Lambea Castro: Los villancicos de Joan Pau Pujol (*1570-†1626)..., vol. IV, p. 194 (edición diplomático-interpretativa en notación moderna). 